\title{
Role of MicroRNAs in Hepatocellular Carcinoma
}

\author{
Zixiang Zhu ${ }^{1}$; Xiangle Zhang ${ }^{1}$; Guoqing Wang ${ }^{2}$; Haixue Zheng ${ }^{1{ }^{1}}$ \\ ${ }^{1}$ State Key Laboratory of Veterinary Etiological Biology, National Foot and Mouth Disease Reference Laboratory, Lanzhou Veterinary Research Institute, Chinese Academy of \\ Agricultural Sciences, Lanzhou, China \\ ${ }^{2}$ College of Veterinary Medicine, Gansu Agricultural University, Lanzhou, China \\ ${ }^{*}$ Corresponding Author: Haixue Zheng, State Key Laboratory of Veterinary Etiological Biology, National Foot and Mouth Disease Reference Laboratory, Lanzhou Veterinary Research \\ Institute, Chinese Academy of Agricultural Sciences, No.1, Xujiaping Road, 730046, Lanzhou, China. Tel: +86-2134293139, Fax:+86-9318342710, E-mail: haixuezheng@163.com
}

Received: March 2, 2014; Revised: April 20,2014; Accepted: June 9, 2014

\begin{abstract}
Context:MicroRNAs (miRNAs) are small, noncoding RNAs that play an important role in posttranscriptional gene regulation and function as negative gene regulators. They are an abundant class of RNA, each of which can control hundreds of gene targets and regulate diverse biological processes such as hematopoiesis, organogenesis, apoptosis and cell proliferation. Aberrant miRNA expression contributes to tumorigenesis and cancer progression.

Evidence Acquisition: In this study we provided a summarized review of the most important new data available on hepatocellular carcinoma (HCC)-associated miRNAs. The data were collected through searching the related keywords and were categorized and summarized in different sections.

Results: Researchers have reported that miRNAs can repress the expression of important cancer-related genes and might be helpful in the diagnosis and treatment of cancer. During the past two decades, numerous studies have shown that miRNAs play an essential role in inhibiting HCC via several different pathways. Deregulated miRNAs may contribute to carcinogenesis, indicating that miRNAs can act as tumor suppressors and oncogenes.

Conclusions: In this mini review, we highlight current findings and discuss recent work to determine the contribution of miRNA expression to the maintenance and growth of HCC, thereby providing a significant source of hope that miRNAs could serve as therapeutic targets.
\end{abstract}

Keywords: Hepatocellular Carcinoma; MicroRNAs; Regulation; Therapeutic Targets

\section{Context}

\subsection{Hepatocellular Carcinoma}

Hepatocellular carcinoma (HCC), the most common primary liver cancer, is the fifth most frequent cancer and the third cause of cancer-related mortality worldwide (1). Worldwide incidence of the disease is over 600,000 cases each year $(2,3)$. HCC normally develops as a consequence of underlying liver disease and is often associated with cirrhosis (4). Incidence is increasing in patients with cirrhosis and other patient subgroups, such as those with human immunodeficiency virus infection or thalassemia $(5,6)$. Hepatitis $\mathrm{B}(\mathrm{HBV})$ and hepatitis $\mathrm{C}(\mathrm{HCV})$ viral infections, the major risk factors for HCC development, lead to liver cirrhosis and account for $75 \%$ of HCC cases $(7,8)$. Other etiologic factors mainly include toxic chemical exposure, alcohol abuse and intake of aflatoxin-contaminated food $(9,10)$.

Currently, there are no well-established effective adjuvant therapies for HCC and control of HCC at the initial stage is the most effective therapeutic strategy available. However, this cancer is difficult to diagnose and confirm at the initial stage. In addition, prognosis re- mains poor for high tumor recurrence and tumor progression. Thus, there is an urgent need to understand the molecular carcinogenic mechanisms of HCC. New research should in addition be focused on developing more therapeutic strategies against HCC. MicroRNAs (miRNAs) have been widely reported to be involved in the development of HCC. Hence, it may be a new target for HCC therapy. In this mini-review, we will discuss some significant miRNAs involved in HCC development with the aim of gaining a better understanding of how miRNAs affect HCC development.

\subsection{Characteristic of miRNAs}

miRNAs are small (21-23 nucleotides), noncoding RNA molecules that down-regulate gene expression by base pairing with 3' untranslated regions (3' UTRs) of target messenger RNAs (mRNAs) $(11,12)$. Lee et al. discovered the lin-4 family in 1993 (13), Since hundreds of similar miRNAs have been identified in plants, animals and viruses through molecular cloning and bioinformatic approaches $(14,15)$. These findings suggest that miRNAs are a large 
family of post-transcriptional regulators and control many developmental and cellular processes in eukaryotic organisms (16).

Studies have shown that miRNAs play an important role in the physiological process of animals and plants, such as growth, development, differentiation and reproduction, and that abnormal expression is closely related to human disease $(17,18)$. miRNAs have emerged as important players in tumorigenesis, which has led to a paradigm shift in oncology. miRNA microarrays have been used to demonstrate that a number of miRNAs function as potential biomarkers for cancer (19). miRNA profiles reflect the developmental lineage and differentiation stages of tumors (11). Many miRNAs have been identified to act as oncogenes, tumor suppressors, or modulators of cancer stem cells and metastasis $(20,21)$. The rapid discovery of many miRNA targets and their relevant pathways has contributed to the development of miRNAbased therapeutics.

\section{3. miRNAs and HCC}

HCC, a common cause of primary malignant tumors, is a multifactorial disease influenced by a variety of risk factors. Although a number of cellular phenomena (such as inflammation and oxidative stress) and molecular events that facilitate tumor initiation, progression and metastasis have been confirmed $(22,23)$, the exact mechanism of HCC has not yet been fully elucidated. miRNAs, a class of molecules that regulates post-transcriptional expression, play an important role in tumorigenesis. The discovery of miRNAs and the emergence of corresponding moleculartargeting therapies have added a new dimension to our efforts for combating HCC.

Recent advances in the study of liver miRNAs using gene-modified mice and in vivo nucleic acid delivery for over-expression of specific miRNAs or inhibition of miRNA function have revealed crucial biological roles for individual miRNAs in physiologically essential liver functions in vivo (24). A number of miRNAs have been shown to be aberrantly expressed during liver cancer development $(25,26)$. In addition, some of these miRNAs might have prognostic significance (27). The aim of this mini review is to discuss current results regarding the molecular aspects of the biological roles of miRNAs in the liver and to explore their relevance to the major and significant molecular mechanisms of cancer occurrence and development.

\section{Evidence Acquisition}

In the present study, we provided a summarized review of the most important new data available on hepatocellular carcinoma (HCC)-associated miRNAs. The data were collected through searching the following related keywords and their different combinations: HCC, miRNA, miRNA regulation, Therapeutic targets, miRNA diagnosis and Carcinoma miRNA. The identified full-text articles were reviewed and the data were summarized in different sections.

\section{Results}

\section{1. miRNAs Down-Regulated in HCC}

\subsection{1. $m i R-122$}

miR-122, a 22-nucleotide miRNA, is a liver-specific, noncoding polyadenylated RNA that accounts for $70 \%$ of the liver miRNA population (28). The miR-122 sequence, transcribed from the $\alpha$-helix coiled coil rod homolog (hcr) gene and the adjacent secondary structure in the hor mRNA are conserved in a wide range of species, including mammals and fish (29). miR-122 is a highly abundant mRNA and is found in human liver, human primary hepatocytes and cultured liver-derived cells, such as the human Huh7 line $(30,31)$, but is undetectable in other tissues $(32)$. Levels of miR-122 in mouse livers increase to half maximal values around day 17 of embryogenesis and reach near maximal levels (50,000 copies per average cell) prior to birth. Studies demonstrating that expression is specifically induced in mouse liver during embryogenesis suggest that miR-122 is involved in liver development (33). Now that it has been established that the miR-122 was significantly involved in liver development, will HBV or HCV sequester miR-122 for the HCC development? Studies that address this and other questions should be performed in the future.

Using computational tools, at least two genes have been predicted to be targets of miR-122 and are of interest in tumorigenesis: the N-Myc gene, which is frequently rearranged in woodchuck liver tumors by the woodchuck hepatitis virus (34), the gene referred to as "down-regulated in liver malignancy" (35) and the cyclin G1 gene (36). The rearrangement or decrease of these genes has been suggested to facilitate HCC development $(34,36)$.

Numerous studies have reported that miR-122 is downregulated in human HCCs (36-39). Esau et al. found miR122 to be a key regulator of cholesterol and fatty-acid metabolism in the adult liver (40). Czech et al. showed that silencing miR-122 resulted in a notable decrease in plasma cholesterol levels, which was consistently associated with a decreased expression of genes involved in cholesterol biosynthesis (41). It revealed the significant role of miR-122 in liver cells. Bai et al. reported that liver-specific miR-122 is frequently suppressed in primary HCC (39). Lin et al. found B-cell lymphoma 2 like protein 2 (Bcl-w), an antiapoptotic gene, to be a direct target of miR-122 that functions as an endogenous apoptosis regulator in HCC-derived cell lines (42). Fornari et al. proved that low miR-122 levels in HCC patients were associated with a shorter recurrence time (43). All of these results suggest that miR-122 is significantly associated with hepatocarcinogenesis and that miR-122 may promote HCC development. Furthermore, a recent study showed that over-expression of miR-122 at an appropriate stage 
could promote hepatic differentiation and maturation by regulating the balance between proliferation and differentiation through a miR-122-FoxA1-HNF4a-positive feedback loop (44). It therefore appears that miR-122 is a favored miRNA for HCC. The down-regulation of miR-122 may be regulated by host defending systems and the decrease in miR-122 may limit the expansion of HCC. Some studies have also reported controversial changes to miR122 in HCC, for example, it's reported a significantly increased level of miR-122 in HCV-associated cancers when compared to non-cancerous tissue (20). We compared these studies and deduced that the different results may have been caused by the diverse detection methods or different samples chosen for analysis. The gender of the patients or the different clinical relevance of HCC may also have resulted in different results. However, to date, most studies have highlighted the decreased expression levels of miR-122 in HCCs compared to normal tissues. All of these results suggest that miR-122 may be an attractive therapeutic target for metabolic disease and as such, provide a significant source of hope that miRNAs could potentially serve as therapeutic targets.

\subsection{2. $m i R-101$}

miR-101 is a tumor-suppressive miRNA. It is significantly under-expressed in multiple types of cancers, including prostate (45), gastric (46), lung $(47,48)$, colon (49) and liver cancer (50), and displays a suppressive effect on cellular proliferation, migration and invasion (51). It appears that the host cells assign positive roles to miR-101; however, viruses that can induce tumor occurrence will surely antagonize the expression of miR-101 to enhance its own replication and the decreased expression of miR101 in tumors may be an achievement on the part of viruses in their bid to defeat host cellular systems.

A study has indicated that miR-101 expression is frequently reduced in human HCC tissues and hepatoma cell lines (50). It is widely known that miRNAs exert their function through regulating the expression of their downstream target genes (12). Myeloid cell leukemia sequence 1 gene (Mcl-1), an antiapoptotic member of the B-cell lymphoma 2 (BCL-2) family (52), is a potential miR101target. Knockdown of $\mathrm{Mcl}-1$ can sensitize cancer cells to apoptosis induced by different stimuli, such as serum starvation (53) or chemotherapeutic drugs (54). Wei et al. showed that miR-101 was frequently down-regulated in HBV-positive HCC tumor tissues when compared with adjacent noncancerous tissues, suggesting that miR-101 may play a tumor-suppressive role in HCC development (55). Of note, it was found that miR-101 expression inversely correlated with DNA (cytosine-5-)-methyltransferase 3 alpha (DNMT3A) expression in HCC and significant down-regulation of miR-101 resulted in DNMT3A up-regulation, which likely occurs during HCC development (55). Zhang et al. confirmed that miR-101 directly targets sex determining region $Y$ related high-mobility group box 9 (SOX9) in HCC, suggesting that miR-101 may suppress
HCC tumor progression by down-regulating SOX9 (56). Furthermore, miR-101 inhibits the expression of the FBJ murine osteosarcoma viral oncogene homolog (FOS) oncogene post-transcriptionally by binding to the 3' UTR of the FOS mRNA, thereby reducing hepatocyte growth factor-induced cell invasion and migration (57). This inhibitive activity of miR-101 possibly directly counteracts the development of HCC. Recently, it was demonstrated that miR-101 represses HCC progression by directly targeting the enhancer of zeste homolog 2 (drosophila) (EZH2) oncogene and sensitizes liver cancer cells to chemotherapeutic treatment (58). Shen et al. proved that miR-101 functions as a tumor suppressor by regulating abnormal Nemo-like kinase (NLK) activity in the liver (59). It has also been reported that targeted disruption of NLK inhibits tumor cell growth by simultaneous suppression of cyclin D1 and CDK2 in human hepatocellular carcinoma (60), which implies the anti-tumor activity of miR-101. Xu et al. found that autophagy was suppressed by miR-101 in the HepG2 HCC cell line via targets, including ras-related protein rab-5A (RAB5A), stathmin 1 (STMN1) and autophagy related $4 D$, cysteine peptidase (ATG4D) (61). Autophagy has been widely reported to facilitate virus replication; the suppression of miR-101 to the appearance of autophagy may indirectly inhibit virus replication.

Overall, the presence of miR-101 may serve as a biochemical marker for monitoring the progression of tumor development in HBV-related HCC; moreover, miR-101 may be a potential prognostic marker and therapeutic target for HCC.

\subsection{3. $m i R-124$}

miR-124 is a brain-enriched miRNA that plays a crucial role in gastrulation and neural development $(62,63)$. miR-124 has been widely reported to regulate a plethora of target proteins involved in cell cycle, differentiation, cellular development and migration $(64,65)$. Recent profile studies of miRNA expression have documented a deregulation of miR-124 in HCC (66).

In HCC cell lines, stable over-expression of miR-124 was sufficient for inhibiting cell motility and invasion in vitro, and additionally, suppressed intrahepatic and pulmonary metastasis in vivo (67). This implies that miR-124 can possibly limit the metastasis of HCC. Zheng et al. demonstrated that the expression levels of miR124 were frequently reduced in HCC cells and tissues, and low-level expression of miR-124 was significantly associated with a more aggressive and/or poor prognostic phenotype of patients with HCC (67). Furuta et al. showed that miR-124 and miR-203 are novel tumorsuppressive miRNAs for HCC that are epigenetically silenced and that activate multiple targets during hepatocarcinogenesis (68). Lang et al. determined that miR-124 functions as a growth-suppressive miRNA and plays an important role in inhibiting tumorigenesis by targeting phosphatidylinositol-4,5-bisphosphate 3-kinase and catalytic subunit alpha (PIK3CA) (69). Zeng et al. indicated that 
low miR-124 levels mediated by HCV via DNA (cytosine-5-)methyltransferase 1 (DNMT1) promote interstitial cells of Cajal cell migration and invasion by targeting SET and MYND domain-containing 3 (SMYD3) (64). Lu et al. showed that miR-124 functions as a tumor suppressor in HCC by targeting the signal transducer and activator of transcription 3 (STAT3) (70). These studies suggest that miR-124 can target various genes in order to suppress HCC development. Conversely, HCC-related viruses, such as HBV and $H C V$ will antagonize the expression of miR-124 and its activity; decreased expression levels of miR-124 may be the result of counteracting by the viruses, however, more studies should be developed in order to better understand this counteracting process.

In summary, the data discussed above highlight an important role for miR-124 in the regulation of invasion and metastasis in the molecular etiology of HCC and suggest the potential application of miR-124 in prognosis prediction and cancer treatment.

\subsubsection{Let-7 Family}

The let-7 miRNA family has 13 members located on nine different human chromosomes. The family was first discovered in Caenorhabditis elegans and is functionally conserved in worms and humans (71). It is widely viewed as a tumor suppressor miRNA. Many human cancers exhibit deregulated let-7 expression when compared to normal tissue (72-74).

Several studies have suggested that lin28s may promote transformation by targeting let-7 and that the intricate balance between lin28 and let-7 may be critical for regulating tumor development and progression $(75,76)$. Johnson et al. demonstrated that human let-7 specifically targets rat sarcoma (RAS) in human cancer cells (77), which was confirmed in non-small cell lung cancer, using a mouse model in which let-7g inhibited tumor growth via the suppression of RAS (78). Recently, several studies have identified the role of let-7 in HCC development. Using microarray analysis, Shimizu et al. found that let-7 miRNAs negatively regulate $B$-cell lymphoma 2 like protein 1 ( $\mathrm{Bcl}-\mathrm{Xl})$ expression and can induce apoptosis when used with an anti-cancer drug targeting myeloid cell leukemia sequence 1 (Mcl-1) in human HCC (79). It's identified that let-7g may partially suppress HCC metastasis through targeting collagen, type I, alpha 2 (COL1A2) (80). The various functions of the let-7 miRNA family involved in DNA replication, apoptosis and cellular differentiation create a collaborative inhibitive effect against HCC development. Hence, restoration of let-7 expression may be a useful therapeutic option for HCC where let-7 expression is absent.

\section{2. miRNAs Up-Regulated in HCC}

\subsection{1. $m i R-221$}

miR-221 has been reported to be over-expressed in many human tumor tissues, such as breast cancer (81), colorec- tal cancer (80), glioblastoma (82) and prostate cancer (83). A recent report shows that miR-221 stimulates the onset of tumors and promotes tumor progression, significantly shortening the mean time to death in a mouse model of liver cancer (84). The promotive roles of miR221 in tumor progression may result from the interfering function of miR-221 against some cellular anti-oncogenes. Tumor progression could potentially stimulate the expression of miR-221 and promote its development.

In highly aggressive HCCs, miR-221 was among the most up-regulated of all miRNAs studied. The key miR-221-targeted tumor suppressors include p27, p57, phosphatase and tensin homolog (PTEN), a tissue inhibitor of metalloproteinase-3 and the DNA damage-inducible transcript 4 (DDIT4 ) (85-87). Li et al. found miR-221 expression to be correlated with tumor size, cirrhosis and tumor stage. Kaplan-Meier survival analysis showed that the overall survival rate of the high miR-221-expression group was significantly lower than that of the low miR-221-expression group (88), implying that serum miR-221 may provide predictive significance for the prognosis of HCC patients. miR-221 is capable of stimulating tumor growth in vivo, possibly through down-regulation of p27 and/or DDIT4 expression. A recent study offers preclinical proof for the efficacy of chol-anti-miR-221 in a valid orthotopic mouse model of HCC, suggesting that this targeted agent could improve treatment for patients with advanced HCC (89). Pineau et al. revealed an important contribution for miR-221 in hepatocarcinogenesis and suggested a role for DDIT4 dysregulation in this process (84). The dysregulation roles of miR-221 in cellular apoptosis and differentiation indicate the negative regulatory effect of miR-221. Thus, the use of synthetic miR-221 inhibitors may be a promising approach for HCC treatment.

\subsection{2. $m i R-224$}

miR-224 is a potential oncogenic miRNA that impacts multiple crucial cellular processes (90). Transfection of miR-124 induced neuronal phenotypic changes by affecting the expression of neuronal-specific markers in stem cells derived from both mouse neural/brain tumor and human glioblastoma multiforme (90). miR-124 is greatly upregulated in human HCC when compared to both paired peritumoral cirrhotic tissues and cirrhotic livers without HCC (91), and plays a role in cell proliferation, migration, invasion and anti-apoptosis (92). It has also been reported that the expression of miR-224 and the host gammaaminobutyric acid (GABA) A receptor, epsilon (GABRE) gene (located on human chromosome band Xq28) increased progressively as normal liver progressed to a benign hepatocellular state (93). Taken together, these results imply a co-carcinogenic role for miR-124.

Histone acetylation was found to play a partial role in the regulation of miR-224 and genes at the Xq28 locus in patients with HCC (94). Wang et al. have shown that miR-224 is coordinately up-regulated with neighboring miR-452 and genes at Xq28 in HCC tumors (94). Scisciani 
Zhu Z et al.

et al. identified that p65/NF- $\mathrm{B}$ (nuclear factor kappa-lightchain-enhancer of activated B cells) is a direct transcriptional regulator of miR-224 expression and links miR-224 up-regulation with the activation of the LPS, LT $\alpha$, and TNF $\alpha$ inflammatory pathways, as well as cell migration/invasion in HCC (95). The negative regulation of miR-224 on NF-kB or other cytokines expression may directly block the antitumoral ability of the host, causing the involved pathways to shift to abnormal status and finally facilitate HCC development. Taken together, these studies suggest that miR224 may represent a promising biomarker for assessing liver status in the case of liver disease and HCC. Some synthetic medicines against miR-124 may potentially suppress or alleviate the development of HCC.

\subsection{3. $m i R-21$}

miR-21 aberrant expression was first identified by miRNA profiling of human glioblastoma (96). Subsequently, miR21 has become one of the most studied miRNAs associated with cancer. miR-21 has been reported to be up-regulated in various types of tumors and it plays an important role in cancer pathogenesis and progression (97). Asangani et al. reported that miR-21 induces invasion, intravasation and metastasis (98). It was significantly up-regulated in HCC tissues and cell lines, compared with adjacent non-tumor tissues and normal hepatic cells. miR-21 up-regulation is associated with the capacity of tumor migration and invasion in HCC. The targets of miR-21 may involve some tumor suppressive factors; therefore, the up-regulation of miR-21 can potentially result in the decrease of some anti-tumor proteins, which finally promote the development of HCC. The relationship between various anti-tumor factors and miR-21 should be studied in future to better understand the roles of miR-21 in HCC development.

Since the aberrant expression of miR-21 was confirmed in the miRNA profiling of human glioblastoma (96), miR-21 has been identified as one of the most important miRNAs dysregulated in cancer, including breast (99), colorectal (98), gastric (97), lung (100) and liver (101) cancers. Meng et al. showed that miR-21 was highly overexpressed in HCC tumors and cell lines in expressionprofiling studies using miRNA microarrays. Inhibition of miR-21 in cultured HCC cells increased expression of the phosphatase and tensin homolog (PTEN) tumor suppressor, and decreased tumor cell proliferation, migration and invasion (102). Whether PTEN is one of miR-21 targeted genes, or if one of the upstream regulatory genes of PTEN is a target gene of miR-21, these genes should be further studied in future.

In both human and woodchuck HCC cell lines, separate treatments with antisense oligonucleotides specific to miR-21 caused a 50\% reduction in both hepatocyte proliferation and anchorage-independent growth (103). These observations suggest that new drugs or antisense oligonucleotides specific to miR-21 may be considered a potential therapeutic strategy for HCC.

\begin{tabular}{|c|c|c|c|}
\hline Expression levels' change in HCC & miRNAs & Association with HCC development & $\begin{array}{c}\text { Target genes } \\
\end{array}$ \\
\hline \multirow[t]{12}{*}{ Down-regulation } & miR-122 & Controversial & N-Myc; Cyclin G1; Bcl-w; ADAM17; Wnt1 \\
\hline & miR-101 & Suppressive & Mcl-1; EZH2; EED;DNMT3A; SOX9 \\
\hline & miR-124 & Suppressive & РIK3CA; STAT3; SNAI2 \\
\hline & let-7 family & Suppressive & Caspase-3; HMGA2; Bcl-xL; c-myc \\
\hline & miR-125a & Suppressive & MMP11; VEGF-A; SIRT7 \\
\hline & miR-125b & Suppressive & LIN28B2; PIGF; Bcl-2 \\
\hline & miR-203 & Suppressive & c-JUN; SOCS3 \\
\hline & miR-139 & Suppressive & ROCK2; c-Fos \\
\hline & miR-1 & Suppressive & ET-1; HSP60 \\
\hline & miR-145 & Suppressive & IRS1; IRS2; Oct4 \\
\hline & miR-138 & Suppressive & CCND3; FAK \\
\hline & miR-7 & Suppressive & PIK3CD; mTOR; p70S6K \\
\hline \multirow[t]{12}{*}{ Up-regulation } & miR-221 & Promotive & CDKN1C/p57; DDIT4;Arnt \\
\hline & miR-224 & Promotive & RKIP; CDC42; CDH1;PAK2; BCL-2; MAPK1;API-5 \\
\hline & miR-21 & Promotive & PTEN; RHOB; PDCD 4 \\
\hline & miR-155 & Promotive & APC; AT1R; SHIP1 \\
\hline & miR-143 & Suppressive & FNDC3B; Bcl-2 \\
\hline & $\operatorname{miR}-373$ & Promotive & PPP6C; TXNIP; RABEP1 \\
\hline & miR-210 & Unclear & VMP1;AIFM3 \\
\hline & miR-182 & Promotive & MTSS1; CYLD; Foxo1 \\
\hline & miR-181b & Suppressive & TIMP3; Mcl-1 \\
\hline & miR-519d & Promotive & CDKN1A/p21; PTEN; AKT3; TIMP2 \\
\hline & miR-550a & Promotive & CPEB $4 ;$ AKT1 \\
\hline & miR-657 & Promotive & TLE1; IGF2R \\
\hline
\end{tabular}




\section{Conclusions}

HCC is one of the most common primary liver cancers and is a major global health problem that sees an increasing number of new cases diagnosed each year. miRNAs play an important role in physiological processes, many of which are involved in hepatocarcinogenesis. Many studies have reported the identification of miRNA biomarkers, their target genes and the possible mechanisms that lead to hepatocarcinogenesis. miR-124 can be chosen as a prognostic factor for HCC occurrence and the upregulation of its target gene DNMT1 may also be applied as a prognosis for HCC development. Some inhibitory medicines against miRNAs that can facilitate HCC development can possibly also be used in HCC therapy in future. The roles of some particular miRNAs are listed in Table 1, which provide references for further study concerning HCC and miRNAs. Understanding the role of miRNAs in the biology of HCC can potentially provide advances and options for HCC treatment, and might be useful for HCC diagnosis. Future research is needed to address and extend the therapeutic potential of miRNAs in inhibiting the progression of HCC. Additionally, miRNAs can provide new sight and targets for the development and research of new medicines against HCC.

\section{Acknowledgements}

Authors are grateful for the assistance provided by colleagues at State Key Laboratory of Veterinary Etiological Biology, National Foot and Mouth Disease Reference Laboratory, Lanzhou Veterinary Research Institute, Chinese Academy of Agricultural Sciences during the writing this manuscript.

\section{Authors' Contributions}

Zixiang Zhu and Xiangle Zhang wrote the draft of manuscript and contributed in revision of the manuscript. Haixue Zheng contributed in study concept, design and revised the article. Guoqing Wang gathered the data.

\section{Funding/Support}

The Zheng Lab is supported by the following funding: the National Natural Science Foundation of China (no. 31302118), the National High Technology Research and Development Program of China (863 Program, 2011AA10A211-1), the High-level Technological Talent Program of Gansu Province (1013JHTA008), the International Atomic Energy Agency (16025/Ro) and the China Agriculture Research System (CARS-39).

\section{References}

1. Yang JD, Roberts LR. Epidemiology and management of hepatocellular carcinoma. Infect Dis Clin North Am. 2010;24(4):899-919.

2. Bruix J, Sherman M, Practice Guidelines Committee AAFTSOLD. Management of hepatocellular carcinoma. Hepatology. 2005; 42(5):1208-36.

3. Siegel R, Naishadham D, Jemal A. Cancer statistics, 2012. CA CancerJ Clin. 2012;62(1):10-29.
4. Huang XB, Li J, Zheng L, Zuo GH, Han KQ, Li HY, et al. Bioinformatics analysis reveals potential candidate drugs for HCC. Pathol Oncol Res. 2013;19(2):251-8.

5. Bosetti C, Levi F, Boffetta P, Lucchini F, Negri E, La Vecchia C. Trends in mortality from hepatocellular carcinoma in Europe, 1980-2004. Hepatology. 2008;48(1):137-45.

6. Jemal A, Siegel R, Ward E, Hao Y, Xu J, Murray T, et al. Cancer statistics, 2008. CA Cancer J Clin. 2008;58(2):71-96.

7. El-Serag HB. Hepatocellular carcinoma and hepatitis $C$ in the United States. Hepatology. 2002;36(5 Suppl 1):S74-83.

8. Lin CL, Kao JH. Hepatitis B viral factors and clinical outcomes of chronic hepatitis B. J Biomed Sci. 2008;15(2):137-45.

9. Lau WY, Lai EC. Hepatocellular carcinoma: current management and recent advances. Hepatobiliary Pancreat Dis Int. 2008; 7(3):237-57.

10. Cabrera R, Nelson DR. Review article: the management of hepatocellular carcinoma. Aliment Pharmacol Ther. 2010;31(4):461-76.

11. Lu J, Getz G, Miska EA, Alvarez-Saavedra E, Lamb J, Peck D, et al MicroRNA expression profiles classify human cancers. Nature. 2005;435(7043):834-8.

12. Griffiths-Jones S, Grocock RJ, van Dongen S, Bateman A, Enright AJ. miRBase: microRNA sequences, targets and gene nomenclature. Nucleic Acids Res. 2006;34(Database issue):D140-4.

13. Lee RC, Feinbaum RL, Ambros V. The C. elegans heterochronic gene lin-4 encodes small RNAs with antisense complementarity to lin-14. Cell.1993;75(5):843-54

14. Liu B, Li J, Cairns MJ. Identifying miRNAs, targets and functions. Brief Bioinform. 2014;15(1):1-19.

15. Bushati N, Cohen SM. microRNA functions. Annu Rev Cell Dev Biol. 2007;23:175-205.

16. Krol J, Loedige I, Filipowicz W. The widespread regulation of microRNA biogenesis, function and decay. Nat Rev Genet 2010;11(9):597-610.

17. Pritchard CC, Cheng HH, Tewari M. MicroRNA profiling: ap proaches and considerations. Nat Rev Genet. 2012;13(5):358-69.

18. Wahid F, Shehzad A, Khan T, Kim YY. MicroRNAs: synthesis, mechanism, function, and recent clinical trials. Biochim Biophys Acta 2010;1803(11):1231-43.

19. Calin GA, Croce CM. MicroRNA signatures in human cancers. Nat Rev Cancer. 2006;6(11):857-66.

20. Lawrie CH. MicroRNAs in Medicine.: Wiley; 2013

21. George GP, Mittal RD. MicroRNAs: Potential biomarkers in cancer. Indian J Clin Biochem. 2010;25(1):4-14.

22. Maki A, Kono H, Gupta M, Asakawa M, Suzuki T, Matsuda M, et al Predictive power of biomarkers of oxidative stress and inflammation in patients with hepatitis $C$ virus-associated hepatocellular carcinoma. Ann Surg Oncol. 2007;14(3):1182-90.

23. Bishayee A, Barnes KF, Bhatia D, Darvesh AS, Carroll RT. Resveratrol suppresses oxidative stress and inflammatory response in diethylnitrosamine-initiated rat hepatocarcinogenesis. Cancer Prev Res (Phila). 2010;3(6):753-63.

24. Takata A, Otsuka M, Yoshikawa T, Kishikawa T, Ohno M, Koike K. MicroRNAs and liver function. Minerva Gastroenterol Dietol. 2013;59(2):187-203.

25. Zhao Y, Jia HL, Zhou HJ, Dong QZ, Fu LY, Yan ZW, et al. [Identification of metastasis-related microRNAs of hepatocellular carcinoma in hepatocellular carcinoma cell lines by quantitative real time PCR]. Zhonghua Gan Zang Bing Za Zhi. 2009;17(7):526-30.

26. Varnholt H, Drebber U, Schulze F, Wedemeyer I, Schirmacher $\mathrm{P}$, Dienes HP, et al. MicroRNA gene expression profile of hepatitis C virus-associated hepatocellular carcinoma. Hepatology. 2008;47(4):1223-32.

27. Li W, Xie L, He X, Li J, Tu K, Wei L, et al. Diagnostic and prognostic implications of microRNAs in human hepatocellular carcinoma. Int J Cancer. 2008;123(7):1616-22.

28. Lagos-Quintana M, Rauhut R, Lendeckel W, Tuschl T. Identification of novel genes coding for small expressed RNAs. Science. 2001;294(5543):853-8.

29. Moroy T, Etiemble J, Bougueleret L, Hadchouel M, Tiollais P, Buendia MA. Structure and expression of hcr, a locus rearranged with c-myc in a woodchuck hepatocellular carcinoma. Oncogene. 1989;4(1):59-65.

30. Chang J, Provost P, Taylor JM. Resistance of human hepatitis delta virus RNAs to dicer activity. J Virol. 2003;77(22):11910-7. 
31. Jopling CL, Yi M, Lancaster AM, Lemon SM, Sarnow P. Modulation of hepatitis C virus RNA abundance by a liver-specific MicroRNA. Science. 2005;309(5740):1577-81.

32. Lagos-Quintana M, Rauhut R, Yalcin A, Meyer J, Lendeckel W, Tuschl T. Identification of tissue-specific microRNAs from mouse. Curr Biol. 2002;12(9):735-9.

33. Chang J, Nicolas E, Marks D, Sander C, Lerro A, Buendia MA, et al. miR-122, a mammalian liver-specific microRNA, is processed from hcr mRNA and may downregulate the high affinity cationic amino acid transporter CAT-1. RNA Biol. 2004;1(2):106-13.

34. Jacob JR, Sterczer A, Toshkov IA, Yeager AE, Korba BE, Cote PJ, et al. Integration of woodchuck hepatitis and $\mathrm{N}$-myc rearrangement determine size and histologic grade of hepatic tumors. Hepatology. 2004;39(4):1008-16.

35. Harada H, Nagai H, Ezura Y, Yokota T, Ohsawa I, Yamaguchi K, et al. Down-regulation of a novel gene, DRLM, in human liver malignancy from $4 \mathrm{q} 22$ that encodes a NAP-like protein. Gene. 2002;296(1-2):171-7.

36. Gramantieri L, Ferracin M, Fornari F, Veronese A, Sabbioni S, Liu CG, et al. Cyclin G1 is a target of miR-122a, a microRNA frequently down-regulated in human hepatocellular carcinoma. Cancer Res. 2007;67(13):6092-9.

37. Kutay H, Bai S, Datta J, Motiwala T, Pogribny I, Frankel W, et al. Downregulation of miR-122 in the rodent and human hepatocellular carcinomas. J Cell Biochem. 2006;99(3):671-8.

38. Nassirpour R, Mehta PP, Yin MJ. miR-122 regulates tumorigenesis in hepatocellular carcinoma by targeting AKT3. PLoS One. 2013;8(11).

39. Bai S, Nasser MW, Wang B, Hsu SH, Datta J, Kutay H, et al. MicroRNA-122 inhibits tumorigenic properties of hepatocellular carcinoma cells and sensitizes these cells to sorafenib. J Biol Chem. 2009;284(46):32015-27.

40. Esau C, Davis S, Murray SF, Yu XX, Pandey SK, Pear M, et al. miR122 regulation of lipid metabolism revealed by in vivo antisense targeting. Cell Metab. 2006;3(2):87-98.

41. Czech MP, Aouadi M, Tesz GJ. RNAi-based therapeutic strategies for metabolic disease. Nat Rev Endocrinol. 2011;7(8):473-84.

42. Lin CJ, Gong HY, Tseng HC, Wang WL, Wu JL. miR-122 targets an anti-apoptotic gene, Bcl-w, in human hepatocellular carcinoma cell lines. Biochem Biophys Res Commun. 2008;375(3):315-20.

43. Fornari F, Gramantieri L, Giovannini C, Veronese A, Ferracin M, Sabbioni S, et al. MiR-122/cyclin G1 interaction modulates p53 activity and affects doxorubicin sensitivity of human hepatocarcinoma cells. Cancer Res. 2009;69(14):5761-7.

44. Deng XG, Qiu RL, Wu YH, Li ZX, Xie P, Zhang J, et al. Overexpression of miR-122 promotes the hepatic differentiation and maturation of mouse ESCs through a miR-122/FoxA1/HNF4a-positive feedback loop. Liver Int. 2014;34(2):281-95.

45. Ambs S, Prueitt RL, Yi M, Hudson RS, Howe TM, Petrocca F, et al. Genomic profiling of microRNA and messenger RNA reveals deregulated microRNA expression in prostate cancer. Cancer Res. 2008;68(15):6162-70.

46. Wang HJ, Ruan HJ, He XJ, Ma YY, Jiang XT, Xia YJ, et al. MicroRNA-101 is down-regulated in gastric cancer and involved in cell migration and invasion. EurJ Cancer. 2010;46(12):2295-303.

47. Yanaihara N, Caplen N, Bowman E, Seike M, Kumamoto K, Yi M, et al. Unique microRNA molecular profiles in lung cancer diagnosis and prognosis. Cancer Cell. 2006;9(3):189-98.

48. Luo L, Zhang T, Liu H, Lv T, Yuan D, Yao Y, et al. MiR-101 and Mcl-1 in non-small-cell lung cancer: expression profile and clinical significance. Med Oncol. 2012;29(3):1681-6.

49. Strillacci A, Griffoni C, Sansone P, Paterini P, Piazzi G, Lazzarini $\mathrm{G}$, et al. MiR-101 downregulation is involved in cyclooxygenase-2 overexpression in human colon cancer cells. Exp Cell Res. 2009;315(8):1439-47.

50. Su H, Yang JR, Xu T, Huang J, Xu L, Yuan Y, et al. MicroRNA-101, down-regulated in hepatocellular carcinoma, promotes apoptosis and suppresses tumorigenicity. Cancer Res. 2009;69(3):1135-42.

51. Smits M, Nilsson J, Mir SE, van der Stoop PM, Hulleman E, Niers $\mathrm{JM}$, et al. miR-101 is down-regulated in glioblastoma resulting in EZH2-induced proliferation, migration, and angiogenesis. Oncotarget. 2010;1(8):710-20.

52. Bae J, Leo CP, Hsu SY, Hsueh AJ. MCL-1S, a splicing variant of the antiapoptotic BCL-2 family member MCL-1, encodes a proapoptotic protein possessing only the $\mathrm{BH} 3$ domain. J Biol Chem. 2000;275(33):25255-61.

53. Austin M, Cook SJ. Increased expression of Mcl-1 is required for protection against serum starvation in phosphatase and tensin homologue on chromosome 10 null mouse embryonic fibroblasts, but repression of Bim is favored in human glioblastomas. J Biol Chem. 2005;280(39):33280-8.

54. Schulze-Bergkamen H, Fleischer B, Schuchmann M, Weber A, Weinmann A, Krammer PH, et al. Suppression of Mcl-1 via RNA interference sensitizes human hepatocellular carcinoma cells towards apoptosis induction. BMC Cancer. 2006;6:232.

55. Wei X, Xiang T, Ren G, Tan C, Liu R, Xu X, et al. miR-101 is downregulated by the hepatitis $B$ virus $X$ protein and induces aberrant DNA methylation by targeting DNA methyltransferase 3A. Cell Signal. 2013;25(2):439-46.

56. Zhang Y, Guo X, Xiong L, Kong X, Xu Y, Liu C, et al. MicroRNA-101 suppresses SOX9-dependent tumorigenicity and promotes favorable prognosis of human hepatocellular carcinoma. FEBS Lett. 2012;586(24):4362-70.

57. Li S, Fu H, Wang Y, Tie Y, Xing R, Zhu J, et al. MicroRNA-101 regulates expression of the $\mathrm{v}$-fos $\mathrm{FBJ}$ murine osteosarcoma viral oncogene homolog (FOS) oncogene in human hepatocellular carcinoma. Hepatology. 2009;49(4):1194-202.

58. Zheng Z, Xu X, Zhang X, Wang A, Zhang C, Huttemann M, et al. Exposure to ambient particulate matter induces a NASH-like phenotype and impairs hepatic glucose metabolism in an animal model. J Hepatol. 2013;58(1):148-54.

59. Shen Q, Bae HJ, Eun JW, Kim HS, Park SJ, Shin WC, et al. MiR-101 functions as a tumor suppressor by directly targeting nemo-like kinase in liver cancer. Cancer Lett. 2014;344(2):204-11.

60. Jung KH, Kim JK, Noh JH, Eun JW, Bae HJ, Xie HJ, et al. Targeted disruption of Nemo-like kinase inhibits tumor cell growth by simultaneous suppression of cyclin D1 and CDK2 in human hepatocellular carcinoma. J Cell Biochem. 2010;110(3):687-96.

61. Xu Y, An Y, Wang Y, Zhang C, Zhang H, Huang C, et al. miR-101 inhibits autophagy and enhances cisplatin-induced apoptosis in hepatocellular carcinoma cells. Oncol Rep. 2013;29(5):2019-24.

62. Lee MR, Kim JS, Kim KS. miR-124a is important for migratory cell fate transition during gastrulation of human embryonic stem cells. Stem Cells. 2010;28(9):1550-9.

63. Cheng LC, Pastrana E, Tavazoie M, Doetsch F. miR-124 regulates adult neurogenesis in the subventricular zone stem cell niche. Nat Neurosci. 2009;12(4):399-408.

64. Zeng B, Li Z, Chen R, Guo N, Zhou J, Zhou Q, et al. Epigenetic regulation of miR-124 by hepatitis $\mathrm{C}$ virus core protein promotes migration and invasion of intrahepatic cholangiocarcinoma cells by targeting SMYD3. FEBS Lett. 2012;586(19):3271-8.

65. Rajewsky N. microRNA target predictions in animals. Nat Genet. 2006;38 Suppl:S8-13.

66. Ura S, Honda M, Yamashita T, Ueda T, Takatori H, Nishino R, et al. Differential microRNA expression between hepatitis $B$ and hepatitis $C$ leading disease progression to hepatocellular carcinoma. Hepatology. 2009;49(4):1098-112.

67. Zheng F, Liao YJ, Cai MY, Liu YH, Liu TH, Chen SP, et al. The putative tumour suppressor microRNA-124 modulates hepatocellular carcinoma cell aggressiveness by repressing ROCK2 and EZH2. Gut. 2012;61(2):278-89.

68. Furuta M, Kozaki KI, Tanaka S, Arii S, Imoto I, Inazawa J. miR124 and miR-203 are epigenetically silenced tumor-suppressive microRNAs in hepatocellular carcinoma. Carcinogenesis. 2010;31(5):766-76.

69. Lang Q, Ling C. MiR-124 suppresses cell proliferation in hepatocellular carcinoma by targeting PIK3CA. Biochem Biophys Res Commun. 2012;426(2):247-52.

70. Lu Y, Yue X, Cui Y, Zhang J, Wang K. MicroRNA-124 suppresses growth of human hepatocellular carcinoma by targeting STAT3. Biochem Biophys Res Commun. 2013;441(4):873-9.

71. Reinhart BJ, Slack FJ, Basson M, Pasquinelli AE, Bettinger JC, Rougvie AE, et al. The 21-nucleotide let-7 RNA regulates developmental timing in Caenorhabditis elegans. Nature. 2000;403(6772):901-6.

72. Yu F, Yao H, Zhu P, Zhang X, Pan Q, Gong C, et al. let-7 regulates 
self renewal and tumorigenicity of breast cancer cells. Cell. 2007;131(6):1109-23.

73. Akao Y, Nakagawa Y, Naoe T. let-7 microRNA functions as a potential growth suppressor in human colon cancer cells. Biol Pharm Bull. 2006;29(5):903-6.

74. Esquela-Kerscher A, Trang P, Wiggins JF, Patrawala L, Cheng A, Ford L, et al. The let-7 microRNA reduces tumor growth in mouse models of lung cancer. Cell Cycle. 2008;7(6):759-64.

75. Viswanathan SR, Daley GQ, Gregory RI. Selective blockade of microRNA processing by Lin28. Science. 2008;320(5872):97-100.

76. Heo I, Joo C, Cho J, Ha M, Han J, Kim VN. Lin28 mediates the terminal uridylation of let-7 precursor MicroRNA. Mol Cell. 2008;32(2):276-84.

77. Johnson SM, Grosshans H, Shingara J, Byrom M, Jarvis R, Cheng A, et al. RAS is regulated by the let-7 microRNA family. Cell. 2005;120(5):635-47.

78. Kumar MS, Erkeland SJ, Pester RE, Chen CY, Ebert MS, Sharp PA et al. Suppression of non-small cell lung tumor development by the let-7 microRNA family. Proc Natl Acad Sci U S A. 2008; 105(10):3903-8.

79. Shimizu S, Takehara T, Hikita H, Kodama T, Miyagi T, Hosui A, et al The let-7 family of microRNAs inhibits Bcl-xL expression and potentiates sorafenib-induced apoptosis in human hepatocellular carcinoma. J Hepatol. 2010;52(5):698-704.

80. Pu XX, Huang GL, Guo HQ, Guo CC, Li H, Ye S, et al. Circulating miR-221 directly amplified from plasma is a potential diagnostic and prognostic marker of colorectal cancer and is correlated with p53 expression. J Gastroenterol Hepatol. 2010;25(10):1674-80.

81. Miller TE, Ghoshal K, Ramaswamy B, Roy S, Datta J, Shapiro CL, et al. MicroRNA-221/222 confers tamoxifen resistance in breast cancer by targeting p27Kip1. J Biol Chem. 2008;283(44):29897-903.

82. Zhang CZ, Zhang JX, Zhang AL, Shi ZD, Han L, Jia ZF, et al. MiR-221 and miR-222 target PUMA to ind uce cell survival in glioblastoma. Mol Cancer. 2010;9:229.

83. Galardi S, Mercatelli N, Giorda E, Massalini S, Frajese GV, Ciafre SA, et al. miR-221 and miR-222 expression affects the proliferation potential of human prostate carcinoma cell lines by targeting p27Kip1. J Biol Chem. 2007;282(32):23716-24.

84. Pineau P, Volinia S, McJunkin K, Marchio A, Battiston C, Terris B, et al. miR-221 overexpression contributes to liver tumorigenesis. Proc Natl Acad Sci U S A. 2010;107(1):264-9.

85. Sarkar S, Dubaybo H, Ali S, Goncalves P, Kollepara SL, Sethi S, et al Down-regulation of miR-221 inhibits proliferation of pancreatic cancer cells through up-regulation of PTEN, p27(kip1), p57(kip2) and PUMA. Am J Cancer Res. 2013;3(5):465-77.

86. Frenquelli M, Muzio M, Scielzo C, Fazi C, Scarfo L, Rossi C, et al. MicroRNA and proliferation control in chronic lymphocytic leukemia: functional relationship between miR-221/222 cluster and p27. Blood. 2010;115(19):3949-59.

87. le Sage C, Nagel R, Egan DA, Schrier M, Mesman E, Mangiola A, et al. Regulation of the p27(Kip1) tumor suppressor by miR221 and miR-222 promotes cancer cell proliferation. EMBO J 2007;26(15):3699-708

88. Li J, Wang Y, Yu W, Chen J, Luo J. Expression of serum miR-221 in human hepatocellular carcinoma and its prognostic significance. Biochem Biophys Res Commun. 2011;406(1):70-3.
89. Park JK, Kogure T, Nuovo GJ, Jiang J, He L, Kim JH, et al. miR-221 silencing blocks hepatocellular carcinoma and promotes survival. Cancer Res. 2011;71(24):7608-16.

90. Silber J, Lim DA, Petritsch C, Persson AI, Maunakea AK, Yu M, et al. miR-124 and miR-137 inhibit proliferation of glioblastoma multiforme cells and induce differentiation of brain tumor stem cells. BMC Med. 2008;6:14.

91. Wang Y, Lee CG. Role of miR-224 in hepatocellular carcinoma: a tool for possible therapeutic intervention? Epigenomics. 2011;3(2):235-43.

92. Zhang Y, Takahashi S, Tasaka A, Yoshima T, Ochi H, Chayama K. Involvement of microRNA-224 in cell proliferation, migration, invasion, and anti-apoptosis in hepatocellular carcinoma. J Gastroenterol Hepatol. 2013;28(3):565-75.

93. Ladeiro Y, Couchy G, Balabaud C, Bioulac-Sage P, Pelletier L, Rebouissou S, et al. MicroRNA profiling in hepatocellular tumors is associated with clinical features and oncogene/tumor suppressor gene mutations. Hepatology. 2008;47(6):1955-63.

94. Wang Y, Toh HC, Chow P, Chung AY, Meyers DJ, Cole PA, et al. MicroRNA-224 is up-regulated in hepatocellular carcinoma through epigenetic mechanisms. FASEB J. 2012;26(7):3032-41.

95. Scisciani C, Vossio S, Guerrieri F, Schinzari V, De Iaco R, D'Onorio de Meo P, et al. Transcriptional regulation of miR-224 upregulated in human HCCs by NFkappaB inflammatory pathways. $J$ Hepatol. 2012;56(4):855-61.

96. Chan JA, Krichevsky AM, Kosik KS. MicroRNA-21 is an antiapoptotic factor in human glioblastoma cells. Cancer Res. 2005;65(14):6029-33

97. Zhang Z, Li Z, Gao C, Chen P, Chen J, Liu W, et al. miR-21 plays a pivotal role in gastric cancer pathogenesis and progression. Lab Invest. 2008;88(12):1358-66.

98. Asangani IA, Rasheed SA, Nikolova DA, Leupold JH, Colburn NH Post S, et al. MicroRNA-21 (miR-21) post-transcriptionally downregulates tumor suppressor Pdcd4 and stimulates invasion, intravasation and metastasis in colorectal cancer. Oncogene. 2008;27(15):2128-36.

99. Frankel LB, Christoffersen NR, Jacobsen A, Lindow M, Krogh A Lund AH. Programmed cell death 4 (PDCD4) is an important functional target of the microRNA miR-21 in breast cancer cells. Biol Chem. 2008;283(2):1026-33.

100. Seike M, Goto A, Okano T, Bowman ED, Schetter AJ, Horikawa I, et al. MiR-21 is an EGFR-regulated anti-apoptotic factor in lung cancer in never-smokers. Proc Natl Acad Sci U S A. 2009;106(29):12085-90.

101. Xu J, Wu C, Che X, Wang L, Yu D, Zhang T, et al. Circulating microRNAs, miR-21, miR-122, and miR-223, in patients with hepatocellular carcinoma or chronic hepatitis. Mol Carcinog. 2011;50(2):136-42.

102. Meng F, Henson R, Wehbe-Janek H, Ghoshal K, Jacob ST, Patel T. MicroRNA-21 regulates expression of the PTEN tumor suppressor gene in human hepatocellular cancer. Gastroenterology. 2007;133(2):647-58

103. Connolly E, Melegari M, Landgraf P, Tchaikovskaya T, Tennant $\mathrm{BC}$, Slagle BL, et al. Elevated expression of the miR-17-92 polycistron and miR-21 in hepadnavirus-associated hepatocellular carcinoma contributes to the malignant phenotype. Am J Pathol. 2008;173(3):856-64. 